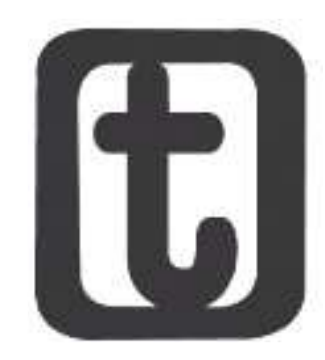

\title{
COMISSÃO DE EMPRESA: ESPAÇO DE INTERLOCUÇÃO PROFISSIONAL E RESISTÊNCIA
}

\author{
Company commission: space of professional interluction and resistance
}

\author{
Márcia Regina Botão Gomes* \\ Maria Elizabeth Freire Salvador** \\ Dácia Cristina Teles Costa***
}

\section{RESUMO}

O presente artigo apresenta uma síntese de um dos seminários promovidos pela Comissão Temática de Empresa do Conselho Regional de Serviço Social CRESS-RJ. Esse espaço tem sido um local de resistência a possíveis distorções da realidade promovendo debates sobre a reestruturação produtiva e trabalho profissional. Com suporte teórico-metodológico de profissionais da área acadêmica e ampla participação de assistentes sociais que atuam ou desejam atuar em empresas, essa Comissão tem se fortalecido como um espaço de interlocução profissional a partir de debates democráticos.

\section{PALAVRAS-CHAVE}

Serviço Social; Empresa; CRESS-RJ; Trabalho.

\section{ABSTRACT}

This article presents a summary of one of the seminars promoted by the company Thematic Commission of the Regional Council of Social Service RJ. This space has been a place of resistance to possible distortions of reality by promoting debates about productive restructuring and professional work. With the theoretical and methodological support of professionals in the academic field and the wide participation of social workers who work or wish to work in companies, this Committee has strengthened as a space for professional dialogue based on democratic debates.

\section{KEYWORDS}

Social Work; Company; CRESS-RJ; Work.

\footnotetext{
* Assistente Social. Doutora em Serviço Social. Professora do curso de Serviço Social da PUC-Rio, Pósgraduação e graduação. (PUC-Rio, Rio de Janeiro, Brasil). Marquês de São Vicente, n 225, Gávea, Rio de Janeiro, CEP: 22451 900. ORC ID: http://orcid.org/0000-0003-2672-3672. E-mail:<mrbotao@yahoo.com.br>. ${ }^{* *}$ Assistente Social. Mestre em Serviço Social. Docente do curso de Serviço Social da Pontifícia Universidade Católica do Rio de Janeiro (PUC-Rio, Rio de Janeiro, Brasil). Marquês de São Vicente, n 225 , Gávea, Rio de Janeiro, CEP: 22451 900. ORC ID: https://orcid.org/0000-0003-0480-6522. E-mail: <bethsalvador@uol.com.br>.

${ }^{* * *}$ Assistente Social. Mestre em Serviço Social. Assistente Social da empresa Petrobras (Petróleo Brasileiro S/A, Rio de Janeiro, Brasil). Avenida República do Chile, $n^{\circ}$ 65, Centro, Rio de Janeiro, CEP: 20211-260. ORC ID: https://orcid.org/0000-0002-8126-8142 E-mail:<daciateles1@gmail.com>.
}

DOI 10.22422/temporalis.2019v19n37p239-252

$(\mathrm{cc}) \mathrm{BY}$ Commons Atribuição 4.0 Internacional (https://creativecommons.org/licenses/by/4.o/deed.pt_BR), que permite copiar e redistribuir o material em qualquer suporte ou formato, bem como adaptar, transformar e criar a partir deste material para qualquer fim, mesmo que comercial. O licenciante não pode revogar estes direitos desde que você respeite os termos da licença. 


\section{comssion oempress temporalis}

\section{INTRODUÇÃO}

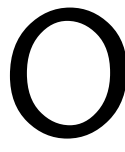

Serviço Social no espaço ocupacional das empresas requer maior atenção nas instituições acadêmicas. As publicações ainda são em número pouco expressivo, se comparadas às publicações referentes a outras áreas do trabalho profissional. Apesar disso, é importante assinalar que o Serviço Social dispõe de um conjunto de bibliografias relevante desde a década de 1980. Contudo, o desafio atual é a manutenção da qualidade das produções bem como sua ampliação considerando o estágio atual do capitalismo e suas inflexões no mundo do trabalho e no modo de viver dos trabalhadores.

O Conselho Regional de Serviço Social do Rio de Janeiro, desde 2011 tem contribuído com o debate sobre a atuação em empresas através da constituição de uma Comissão formada por profissionais que trabalham em instituições de distintos segmentos e portes, contando também com a participação de estudantes do curso de graduação e pós-graduação. $O$ objetivo da Comissão consiste em debater conteúdos relacionados ao trabalho profissional enfatizando a atuação em empresas públicas e privadas e áreas afins. Neste espaço, são discutidos assuntos como: saúde do trabalhador, recursos humanos, benefícios, responsabilidade social e ambiental, além de temas transversais ao cotidiano do trabalho profissional em diferentes campos - autonomia, sigilo, demandas institucionais e profissionais, dentre outros.

Nesse espaço coletivo e plural, a Comissão busca promover debates sobre a contribuição do Serviço Social, suas possibilidades e limites de atuação em empresas considerando as contradições do modo de produção capitalistas vivenciadas no cotidiano profissional. Aspectos como os processos de reestruturação produtiva, conjuntura política e econômica do cenário internacional e nacional, reordenamento papel do Estado diante da hegemonia do capital financeiro, dentre outros são considerados e articulados às particularidades da área empresarial.

A Comissão Temática de Empresa do CRESS-RJ tem realizado reuniões mensais, bem como seminários e palestras com exposições de caráter teórico-prático, sempre que possível. Ao longo de sua existência, a Comissão organizou cinco seminários, todos com ampla adesão e participação de assistentes sociais, o que demonstra a demanda por debates que perpassam o cotidiano do trabalho dos assistentes sociais em empresas.

Em continuidade a esse empenho, a Comissão mantém encontros periódicos em sua sede. O último seminário estadual foi realizado em dezembro de 2016 com o tema Conjuntura e cotidiano do Serviço Social de empresas.

O encontro contou com uma exposição em formato de mesa com o título Conjuntura do século XXI e o exercício profissional em empresas e com debates promovidos a partir de uma oficina em que as participantes foram estimuladas a discorrer sobre o papel do Serviço Social em empresas. Essa dinâmica mais participativa - coordenada por docentes de graduação, pós-graduação e profissionais que trabalham na área - foi muito rica e nos instigou a socializar essa experiência.

Na dinâmica da atividade, os assistentes sociais responderam de forma breve sobre as seguintes questões: Qual é o papel do Serviço Social na área empresarial hoje? Quais são 
os limites e possibilidades para a atuação profissional no cotidiano do trabalho? Esse momento participativo foi registrado como um relatório, o qual será compartilhado neste artigo - não se trata de uma transcrição literal, tampouco serão esgotados os temas presentes no debate - através de uma síntese expositiva constituída de elementos que necessitam reflexões e que suscitaram um intenso debate.

O artigo destacará algumas reflexões a partir das questões apresentadas nesta oficina, e como ponto de partida para a sistematização e socialização dos debates realizados nos encontros de profissionais organizados pela Comissão Temática de Empresa do CRESS elencamos cinco objetivos centrais dessa iniciativa. São eles: $1^{\circ}$ ) Estimular ao debate teórico-prático sobre o Serviço Social em empresas; $2^{\circ}$ ) destacar a importância do Serviço Social para a classe trabalhadora atendida no local de trabalho; $3^{\circ}$ ) Valorizar e dar visibilidade a essa fatia de mercado que permanece contratando assistentes sociais; $4^{\circ}$ ) Contribuir para a qualificação do trabalho profissional; e $5^{\circ}$ ) Fortalecer o debate coletivo, visto que um dos principais desafios atuais se encontra no isolamento fragmentador da classe trabalhadora.

Desse modo, a exposição do conteúdo deste artigo será organizada em três momentos: o primeiro momento fará uma breve reflexão sobre o papel dos assistentes social em empresas; o segundo abordará os principais limites identificados pelos assistentes sociais; e o terceiro, as possibilidades apresentadas pelas profissionais.

\section{O TRABALHO DO ASSISTENTE SOCIAL EM EMPRESAS}

O trabalho dos assistentes sociais em empresas em linhas gerais não se difere do trabalho do Serviço Social no mercado de trabalho, embora possua particularidades que necessitam ser consideradas como ocorre em todo e qualquer espaço socio-ocupacional. Ao longo dos anos de existência da profissão, alguns pesquisadoras se debruçaram sobre essa temática, dentre elas destacam-se Freire (2010), Cesar (1998, 2010), Mota (1991), Mota e Amaral (1998), Botão Gomes (2010, 2015a, 2015b), Giampaoli (2012), Cardoso; Francisco (1998), Doher (2015), dentre outras.

No conjunto dessas produções é possível identificar que muitas mudanças ocorreram na sociedade capitalista incidindo direta e indiretamente no trabalho profissional. Requisições, demandas e desafios profissionais se modificaram e permanecem em constante mutação. Portanto, debates, estudos e pesquisas sobre esta área profissional são necessários.

Parte-se do conhecimento de que o Serviço Social nas empresas permanece sendo uma necessidade social repleta de contradições do modo de produção capitalista. Essa característica própria da profissão se mantém e se expressa nos diversos espaços socioocupacionais, onde o trabalho dos assistentes sociais é desenvolvido, seja nas áreas da saúde, educação, sociojurídico, assistência social, entre outras.

Abordar a área empresarial implica no empenho de desvendar as particularidades da profissão nesse espaço socio-ocupacional, considerar os aspectos comuns à profissão e em relação às demais áreas do trabalho profissional, bem como suas conexões com a totalidade social. 


\section{comssiso o Empress temporalis}

Sendo o trabalho profissional polarizado pelas lutas de classe, o Serviço Social também participa do processo social, reproduzindo as contradições próprias da sociedade capitalista, ao mesmo tempo e pelas mesmas atividades pelas quais é chamado a reforçar as condições de dominação. Se, de um lado o profissional é solicitado a responder às exigências do capital, de outro, participa, ainda que subordinadamente, de respostas às necessidades legítimas de sobrevivência da classe trabalhadora (IAMAMOTO; CARVALHO, 2013).

Seguindo essa reflexão, lamamoto (2010) aprofundou suas análises sobre o Serviço Social, ao longo dos anos, reafirmando que se trata de uma profissão inserida na divisão social e técnica do trabalho que, portanto, sofre os impactos da alienação do trabalho. Os assistentes sociais são profissionais que vendem a sua força de trabalho de forma subordinada em relação ao capital, assim o trabalho profissional é desenvolvido a partir de possibilidades e limites.

O Serviço Social sendo parte e expressão da sociedade pode transformar e é transformado pela realidade em seu constante movimento. Deste modo, todas as áreas de atuação profissional fazem parte da dinâmica das relações sociais, se constituem e se expressam dentro dessa totalidade histórica.

Em síntese, o trabalho profissional desenvolvido por assistentes sociais em empresas possui particularidades, mas também se realiza com dilemas e contradições semelhantes a outros espaços socio-ocupacionais, pois estamos falando de um trabalho remunerado, organizado nos limites do capitalismo, nos quais sua requisição se dá pelo conhecimento que possibilita análise crítica e atendimento de situações que no contexto organizacional é facilmente denominada como problemas, mas que são expressões da "questão social" na vida objetiva e subjetiva dos trabalhadores.

Essa visão resulta em outra qualidade de abordagem com os usuários e, também, em posicionamentos e respostas que os assistentes sociais têm imprimido às demandas sociais dos diferentes grupos e classes sociais.

Considerando as reflexões feitas na oficina realizada no encontro, em dezembro de 2016, as profissionais participantes destacaram como principais papéis na área empresarial: 1) Intermediação de conflitos entre capital-trabalho; 2) Busca de garantia de direitos dos trabalhadores através de políticas públicas ou do conjunto de serviços oferecidos pelas empresas contratantes; 3) Atuação para a melhoria da saúde e qualidade de vida dos trabalhadores; 4) Melhoria no ambiente de trabalho; 5) Negociação de demandas de interesse dos trabalhadores interferindo nas normas e processos institucionais; e 6) Auxílio na organização de reivindicação da classe trabalhadora para o enfrentamento de diferentes expressões da "questão social".

As (os) assistentes sociais atuam em diversas áreas das empresas, podendo vincular-se a áreas de saúde do trabalhador, a programas de responsabilidade social, treinamentos e capacitações, benefícios, dentre outros. Algumas dessas atribuições podem ser distribuídas em diversos setores das organizações. 
A existência e lugar ocupado na estrutura das organizações dependem do porte da empresa, de disputas internas, das estratégias de mercado, entre outros fatores. Os serviços podem ser prestados até mesmo externos à empresa principal sob a modalidade de consultoria terceirizada externa'.

O Serviço Social nas empresas vem adquirindo na atualidade alguns formatos aparentemente inovadores, tais como: trabalho terceirizado, serviço de ouvidoria e as consultorias. Mas o predomínio das atividades profissionais, segundo o relato do grupo participantes da oficina ainda se concentra em orientações e encaminhamentos dos trabalhadores para diferentes serviços e realização de programas e projetos.

Esse dado não pode ser generalizado, pois as (os) profissionais presentes na oficina com um número aproximado de 30 integrantes eram na maioria trabalhadoras (es) de empresas com vínculo de trabalho com tempo indeterminado e com prestação de serviço interno. Para essas (es) profissionais, as atividades têm sido realizadas diante de alguns desafios que serão apresentados sinteticamente no próximo tópico².

\section{OS PRINCIPAIS LIMITES DESTACADOS PELAS ASSISTENTES SOCIAIS PARTICIPANTES DO SEMINÁRIO}

De acordo com a exposição das participantes, foi possível identificar dois grupos de limites, sistematizados no momento da realização da oficina. O primeiro se refere à natureza estrutural e conjuntural do capitalismo que incide nas profissões de um modo geral e o Serviço Social, não é exclusivo, tampouco alheio a esse processo. O segundo se revela como um desdobramento do primeiro e se refere às incidências da atual conjuntura na dimensão ético-política da profissão.

O Serviço Social é uma profissão contraditória, formada por uma categoria profissional contratada por capitalistas ou pelo Estado para prestação de serviço aos trabalhadores, e num contexto de crise e de reordenamento da intervenção Estatal sob uma lógica ultraliberal, que privilegia uma política de redução do investimento público em políticas sociais, a correlação de forças estabelecida tende a reduzir o potencial de conquistas e avanços dos direitos aos trabalhadores.

Segundo Netto (2012), o capitalismo no século XXI tem dado provas de menosprezo pelas formas de civilização democráticas com base em direitos sociais, ao contrário, amplia formas de barbárie para garantia da maximização dos lucros e acumulação capitalista, expressas principalmente nas políticas sociais minimalistas do Estado, forte investimento na área econômica e o frequente uso do militarismo.

Nesse cenário, as (os) assistentes sociais encontram-se diante de processos complexos e de grandes dificuldades, assim como os demais trabalhadores e trabalhadoras. Pois, são

\footnotetext{
${ }^{1}$ Nesses casos, sugerimos algumas leituras críticas das "chamadas consultorias", pois nesses casos as (os) trabalhadoras (os) têm exercido a sua função sob um duplo controle, com maiores restrições de recursos e autonomia, menores salários e menos direitos sociais. Para maior aprofundamento sobre o tema, ver Botão Gomes (2010, 2015a, 2015b e 2018) e Giampaoli (2012).

${ }^{2}$ As dificuldades apresentadas, neste artigo, não reflete a realidade de assistentes sociais que trabalham nas chamadas “consultorias externas". Essas apresentam características mais agudas dos processos de precarização do trabalho.
} 


\section{comssio o enmeress temporalis}

profissionais que buscam a ampliação desses direitos por meio de políticas públicas ou mesmo dos chamados benefícios corporativos - próprios da chamada "cidadania fordista", os salários indiretos. Não por acaso as participantes destacaram algumas dificuldades que serão pontuadas a seguir separadas didaticamente em dois grupos de temas.

\section{Primeiro grupo: Elementos estruturais e conjunturais que incidem no trabalho das (os) assistentes sociais}

Apresentaremos pontual e resumidamente os principais aspectos levantados no encontro: 1) dificuldade de afirmar o espaço ocupacional; 2) falta de autonomia; 3 ) dificuldade de esclarecer o trabalho do Serviço Social para o empregador e para os empregados; 4) desconhecimento ou preconceito com relação ao trabalho do assistente social confundindo-o com práticas assistencialistas; 5) desconstrução, redução de política de atendimento; 6) rotineiras e práticas preestabelecidas; 7) condição de assalariamento que remete ao medo do desemprego; 8) gerência sem visão social; 9) falta de espaço para apresentação de propostas; 10) multifuncionalidade e excesso de trabalho; 12) presença da ideologia neoliberal; 13) poucos recursos e mudanças de gestão; 15) dificuldade de sistematizar o trabalho profissional por falta de tempo.

Com relação ao primeiro grupo de elementos apresentados é possível identificar questões antigas da profissão e outras relativamente recentes. A dificuldade de afirmar o espaço socio-ocupacional não possui uma causa específica, mas se refere a vários aspectos que resultam de um contexto econômico adverso em que se diversificam as formas de dominação, controle e busca do aumento dos lucros e de resultados.

Disso resulta a multiplicidade das demandas institucionais e, em consequência, ações realizadas pelo Serviço Social, em razão das particularidades de cada espaço. Neste contexto, ainda há o desconhecimento de atores institucionais, até o baixo interesse da instituição em investir realmente em ações que favoreçam o trabalhador, pois isso significa o aumento de salário indireto. Ao contrário dos discursos para justificar a adoção e o desenvolvimento de uma política de responsabilidade social, a prioridade empresarial é e sempre será a lucratividade.

Para melhor compreensão desses limites é fundamental revisitar a literatura sobre Serviço Social em empresas e uma delas versa sobre o conceito de empresa cidadã, problematizada por Cesar (2008). A crítica a esse modelo é necessária e consistente por ser uma estratégia de gestão empresarial, portanto, busca essencialmente a acumulação travestida de compromisso social voltada para minimizar as mazelas e desigualdades sociais.

No entanto, cabe considerar que há muitos assistentes sociais que desenvolvem programas e projetos sob a alcunha de responsabilidade social empresarial, também enfrenta grandes dificuldades institucionais, pois se embrenham nas contradições postas nesta relação entre a busca da legitimação social por meio da "filantropia empresarial" e a possibilidade de atender as demandas postas pelos usuários "beneficiados" por essa natureza de política e investimentos. Ou seja, há projetos em disputa, tanto interna, quanto externa a empresa, que pode explicitar a dimensão coletiva do que se pretende apaziguar por meio de atuações pontuais. 
O debate sobre a falta de autonomia foi muito intenso no encontro, sendo compreendida a necessidade de se reiterar a existência de uma real subordinação do trabalho assalariado, hoje ampliada pelo aumento do controle e pelo incremento nos modelos de gestão de cunho predominantemente toyotista do trabalho e do uso das tecnologias.

O tema da autonomia, não é algo novo na profissão, lamamoto (2010) ao longo dos anos tem chamado a atenção para "autonomia relativa", ou seja, o profissional de Serviço Social em seus atendimentos tem possibilidades de escolhas que são norteadas pela competência teórica, política e técnica, mas não possui uma liberdade total e irrestrita para realizar suas tarefas. O que se destaca no estágio atual é a redução das possibilidades objetivas no trabalho profissional diante dos diferentes e sofisticados métodos de controle dos trabalhadores em geral. Não se trata de algo restrito às (aos) assistentes sociais.

Com o uso de tecnologias específicas os empregadores passam a ter recursos para determinar a quantidade de tempo para os atendimentos, burocratizar os processos interferindo cada vez mais nos objetivos profissionais. Essas mudanças são desenvolvidas pelas organizações, sendo naturalizados e, muitas vezes, severamente ofuscados por meio de atividades fragmentadas de um trabalho repetitivo e rotineiro, onde o assistente social não faz a distinção entre as atividades da profissão que lhes dão identidade e as atividades organizacionais. Fato esse próprio dos diversos espaços socio-ocupacionais, mas nas empresas os recursos e sofisticação para "modernizar" práticas antigas e conservadoras são inúmeros.

Outra percepção presente no debate foi referente ao preconceito existente com relação ao trabalho do assistente social, que é frequentemente confundindo com práticas assistencialistas. Ao longo do debate foi proposta a reflexão sobre até que ponto isso é real? Até que ponto não se trata de uma mera confusão do conceito, mas sim de uma negação dos direitos dos trabalhadores própria dos princípios neoliberais e do conservadorismo existente em nossa sociedade que reafirmam os princípios da meritocracia como um valor organizacional?

Desse modo, tudo que se relaciona à busca e ampliação de direito passa a ser desqualificado como "assistencialista" e que deve ser combatido. Sobre essa questão não se pode afirmar veementemente, mas é possível pensar sobre ela futuramente para sermos mais propositivos e esclarecedores, buscando recursos institucionais internos e externos para tornar mais claras as propostas da profissão. Um das possibilidades encontra-se em realizar trabalho articulados aos setores pares com suporte da comunicação interna. Como, por exemplo, a criação de boletins, informativos online, usar espaços de jornais e revistas institucionais, realizar campanhas etc..

Intensificação do trabalho e multifuncionalidade, também, foram destacadas nas falas das (os) assistentes sociais, como um fenômeno em curso desde os anos 1990 e que vem se agravando ao longo da última década. Esse elemento compromete a qualidade do trabalho, a possibilidade de investimento em estudos e pesquisas, pelo desgaste que esse trabalho intensificado pode provocar e comprometer a saúde de quem trabalha nos aspectos físico e mental.

Desse modo, o tempo retirado do trabalhador não só prejudica a sua vida pessoal e de quem está ao seu redor, compromete também a qualidade do próprio profissional. Em 
tempos de descarte dos direitos do trabalho e de outras formas de proteção do trabalhador, os seus corpos e mentes também passam a ser descartados.

Sendo assim, o tema da saúde dos trabalhadores apareceu nesse encontro profissional. Mesmo não sendo uma novidade, novas dimensões têm sido ampliadas atualmente diante da enorme insegurança no emprego, da competitividade e do baixo investimento na área social decorrentes dessa realidade gerando o que Freire chamou de "carga social" (FREIRE, 2010). Essa denominação busca contemplar aspectos da saúde do trabalhador para além das dimensões psicológicas e biológicas de caráter neoliberal que omitem as determinações sociais da saúde.

Os retrocessos mencionados potencializam-se diante da ampliação do conjunto de contrarreformas trabalhistas instauradas desde a década de 1990, agravadas no governo de Michel Temer (2016-2018) e no estágio atual tendem a ser mais radicalizadas com o governo de Jair Bolsonaro.

Antunes (2018) apresenta um balanço importante dos governos brasileiros nas primeiras décadas do século XXI, auxiliando na compreensão das configurações do trabalho no Brasil destacando a nova morfologia do trabalho, bem como as novas formas e os modos de ampliar a exploração do trabalho, tendo como aspecto central os processos de terceirização intensificados em todo mundo, sendo no Brasil legalizado para todos os setores de trabalho3.

Para Fontes (2012), esses processos apresentam expropriações de segunda ordem, ou seja, expropriações dos direitos do trabalho, uma vez que os trabalhadores da sociedade capitalista já não possuem meios de produção. A autora afirma que:

\begin{abstract}
A ameaça recorrente do desemprego aprofunda-se nos países centrais por meio da expropriação de direitos que limitavam a disponibilização da força de trabalho; modificações perversas nas modalidades de contratação de força de trabalho intensificam-se indiscriminadamente. Aprofundam-se a disponibilidade permanente, 'livre', de enorme parcela da força de trabalho, e o fenômeno vem ocorrendo também entre estratos de trabalhadores que se acreditavam protegidos de tal eventualidade. Recompõem-se duras hierarquias no processo de trabalho, de maneira a sobrepor a já acirrada concorrência imposta pelo capital de forma difusa e esparsa, como 'necessidade natural', uma concorrência interna, entre trabalhadores com direitos contratuais profundamente diversos e, mesmo, desprovidos de direitos associados ao trabalho (FONTES, 2012, p. 66).
\end{abstract}

Esses traços da organização do trabalho atual tendem a ser agravados na conjuntura política e econômica do Brasil, por ser um país que não atingiu patamares de cidadania nos moldes do capitalismo avançado. Essa realidade põe em risco a vida de milhares de trabalhadores empregados e desempregados. Pois ocorre, de acordo com Linhart (2007, 2014), um processo de precarização da vida dos trabalhadores decorrentes das novas formas de gestão do trabalho e que, segundo sua hipótese, essa precarização pode ser um dos motivos do aumento do suicídio de trabalhadores (as). Esse aspecto não será

\footnotetext{
${ }^{3}$ Legalização através da Lei no 13.429, de 31 de março de 2017, conhecida como lei da terceirização (BRASIL, 2017). Esta Lei altera os dispositivos da Lei $n^{\circ} 6.019$, de 3 de janeiro de 1974, que dispõe sobre o trabalho temporário nas empresas urbanas e dá outras providências; e dispõe sobre as relações de trabalho na empresa de prestação de serviços a terceiros.
} 
desenvolvido neste artigo, mas é de essencial resgatarmos os estudos relacionados a esses temas, a partir do referencial teórico do Serviço Social, para não cairmos na cilada "psicologizante" da vida social. O suicídio tem se tornado uma das expressões mais agudas da "questão social".

\section{Segundo grupo: elementos ético-políticos apresentados pelas assistentes sociais}

As (os) assistentes sociais destacaram como principais questões encontradas nas empresas onde trabalham: 1) dificuldade de cumprir as exigências do Código de Ética profissional frente aos interesses institucionais; 2) falta de controle sobre o próprio processo de trabalho; 3) colegas que não se percebem como categoria; 4) subordinação a uma gerência que busca o controle da informação buscando interferir no sigilo profissional; 5) contradição entre a identidade profissional e a realidade social.

Este segundo grupo de temas está relacionado ao primeiro sendo igualmente importante e desafiador. Sobre o primeiro aspecto as profissionais apontaram a falta de salas para atendimento, e quando o trabalho é interdisciplinar com atendimento em casa, não se sentem a vontade para conversar com os (as) trabalhadores (as) atendidos (as), uma vez que os sistemas compartilhados nem sempre garantem a segurança da informação. Apesar disso, o que algumas participantes classificaram como dificuldades de cumprir as exigências éticas, nos pareceram confuso, com os princípios éticos diante do contexto de retrocesso dos direitos.

Sobre a falta controle dos próprios processos de trabalho e o aumento do controle por parte dos gerentes indicam que determinados argumentos democráticos da gestão moderna, não se realizam no cotidiano profissional, mas ao contrário, se tornam cada vez mais antidemocráticos no contexto de fragilidade do emprego. A figura do gerente controlador das atividades profissionais e, também, da vida privada dos (as) trabalhadores (as) parece não ter sido abandonada e convive concomitante com as atividades prática ditas modernas, flexíveis, participativas e menos hierárquicas. Cabe às (aos) assistentes sociais respeitarem o sigilo profissional.

Nesse contexto, não eventualmente as (os) trabalhadoras (es) não se veem como tal. Conforme mencionado pelas participantes: "as colegas não se percebem como categoria". Esse dado empírico revela a fragilidade política não só da categoria profissional de assistentes sociais, como também dos (as) demais trabalhadores (as) no contexto do capitalismo atual. O que seria nos dias atuais, se identificar com a classe trabalhadora? Certamente, não podemos igualar o conjunto de trabalhadores (as) aos operários do século XIX, apesar disso, não podemos ignorar os elementos de continuidade que se mantém no conjunto heterogêneo de trabalhadores da sociedade capitalista. Nesse caso, faz-se necessário apresentar brevemente o que entendemos por classe trabalhadora.

A concepção clássica de classe, desenvolvida por Marx e Engels (1977), tornou-se para alguns autores uma categoria superada, sendo alegado que esse sentido clássico seria insuficiente para explicar detalhadamente os desdobramentos contemporâneos, considerado o período em que Marx e Engels escreveram. Pois, quando a sociedade burguesa está expandindo seus princípios e formas de dominação, a configuração da organização do trabalho não tinha o mesmo nível de complexidade dos dias atuais. De fato, 


\title{
comssio o E Empersa temporalis
}

a classe trabalhadora não é exatamente igual à classe trabalhadora do século XIX. Então, como se constituem as classes hoje?

\begin{abstract}
Pensar nas classes trabalhadoras hoje, porém, exige ir além do proletariado e operariado, ou trabalhador fabril. O trabalhador pode ser 'produtivo' (participa na elaboração de mais-valia) ou 'improdutivo' (sem produzir mais-valia). Pode participar da indústria, do comércio ou da empresa financeira (estes últimos, embora não produzindo mais-valia, desenvolvendo trabalho não pago, e participando na valorização do capital, mediante a apropriação da mais-valia já produzida). A classe envolve trabalhadores do 'chão de fábrica', de setores administrativos e de serviços no setor industrial, servidores públicos, trabalhadores autônomos, balconistas de comércio, funcionários de organizações civis, etc. Eles podem ter contratos temporários ou estáveis, ganhar salário fixo ou por comissão ou 'salário por tempo' e 'por peça', (MARX, 1980, p. 626-645), com direitos trabalhistas ou não. Eles podem representar o setor mais empobrecido da população, integrar grupos de consumo médio ou apresentar um elevado padrão de vida (setores baixo, médio e alto da economia). Podem possuir uma força de trabalho desqualificada ou altamente qualificada. Podem apresentar uma relação direta e formal, ou apresentar uma relação informal com o capital (a exemplo dos trabalhadores terceirizados, os camelôs, as microempresas subcontratadas, etc.) (MONTÃNO; DURIGUETO, 2010, p. 94).
\end{abstract}

Com base nesses elementos, que compõem o entendimento de classe trabalhadora, consideramos o assistente social integrante deste grupo, mesmo quando desenvolve suas atividades de forma terceirizada e externa à instituição contratante dos seus serviços, como tem ocorrido na área empresarial a partir da década de 1990. Somos profissionais que vendemos a nossa força de trabalho para obtermos sobrevivência, esse aspecto político da profissão é fundamental para evitar análises parciais dos processos de trabalho e dos atendimentos prestados.

A contradição entre a identidade profissional, seus objetivos e a realidade social, apesar se traduzir em mais uma dificuldade profissional, é um aspecto positivo, pois significa que a profissão apesar de todas as dificuldades apontadas tem persistido em lutar pela garantia dos princípios atuais. Uma tarefa árdua, mas necessária não só por uma manutenção político-ideológica, mas por um compromisso com uma sociedade mais justa e igualitária. É fundamental compreender que a resistência é necessária e deve ser buscada coletivamente, dentro e fora das instituições contratantes.

\section{POSSIBILIDADES APONTADAS PELAS PROFISSIONAIS}

$\mathrm{Na}$ condição de pesquisadoras, docentes e assistentes sociais identificamos por meio de pesquisas que o controle sobre o trabalho tem sido ampliado nas diversas profissões, e o Serviço Social como parte do conjunto dos trabalhadores vem sofrendo as incidências dessas mudanças instaladas nas empresas, no Estado e em toda sociedade. Mesmo diante de um cenário adverso, nesse encontro de assistentes sociais foram destacadas algumas possibilidades profissionais para o fortalecimento dos objetivos profissionais.

As (os) participantes destacaram: a necessidade de reflexões coletivas das (os) assistentes sociais para articulação com todos os demais segmentos de trabalhadores de empresas; buscar meios de divulgação e propagação do trabalho para dar visibilidade às ações desenvolvidas; contribuir para o atendimento das demandas dos (as) trabalhadores (as)

Temporalis, Brasília (DF), ano 19, n. 37, p. 239-252, jan./jun. 2019. ISSN 2238-1856 
com relação às condições de trabalho; negociar com os gestores para uma atuação mais efetiva nos programas e projetos de qualidade de vida e saúde preventiva; buscar sempre que possível atuar numa perspectiva multiprofissional e interdisciplinar nas equipes de saúde; atuar nas comissões de saúde; mensurar os resultados do trabalho; ampliar os campos de atuação propondo programas e projetos que desenvolva os temas de gênero e diversidade; colaborar na ampliação do acesso a informação e direitos.

Essas ações apontadas como possibilidades para os assistentes sociais nas empresas são desempenhadas por muitas (os) participantes, além de outras funções que não cabem neste artigo devido aos seus limites. O campo das possibilidades não é algo vago ou inatingível, mas possui uma dimensão concreta e objetiva, fundada nas bases teóricas e ético-políticas da profissão e da sua essencialidade interventiva.

Sem desconsiderar a condição de trabalhador, as (os) assistentes sociais em algumas situações podem ressignificar as demandas e requisições que chegam, aprimorando-as para uma qualificação de seu trabalho, caso contrário seremos meros burocratas correndo risco de substituição por profissionais técnicos capazes de inserir dados em sistemas préestabelecidos.

Acreditamos que apesar do contexto adverso, grande parte dos (as) profissionais de Serviço Social possui competência e conhecimento para resistir aos ataques aos direitos sociais, sobretudo os que buscam o fortalecimento na coletividade, como tem sido o caso desta Comissão Temática. É sabido que as condições socialmente determinadas nos impedem de muitas coisas, mas história é imensamente rica para ter apenas uma resposta.

\section{CONSIDERAÇÕES FINAIS}

O texto desenvolvido a partir do material sistematizado da participação das (os) assistentes sociais no seminário indica ser importante para as (os) assistentes sociais o reconhecimento do seu trabalho na área empresarial, pois tem sido historicamente um espaço socio-ocupacional onde a (o) assistente social trabalha com e como trabalhador (a) no seu processo de trabalho. Essa particularidade o difere de outras áreas e possibilita à (ao) profissional estar perto dos processos de trabalho desempenhado pelos sujeitos atendidos, exigindo buscar aprimoramento constante para evitar que suas funções se tornem rotineiras e destituídas dos conteúdos centrais da profissão.

A Comissão Temática de Empresa não possui condições de atender todas as demandas profissionais de capacitação, debates etc., assim como as universidades também não, pois os limites e os desafios profissionais não são de fácil solução nem de responsabilidade exclusiva dos profissionais. Mas certamente as trocas promovidas nas Comissões Temáticas do CRESS-RJ, bem como as atividades desenvolvidas no meio acadêmico podem favorecer o aprimoramento profissional auxiliando no fortalecimento de todos os envolvidos.

Discutir sobre o trabalho profissional, os diferentes limites e desafios de forma coletiva nos fornece possibilidades de pensar a superação de boa parte das dificuldades encontradas no cotidiano profissional. Por isso, a Comissão Temática de Empresa tem se esforçado para a realização de seminários e manutenção de encontros temáticos para auxiliar os profissionais no exercício da troca de experiências e conhecimentos importantes para o 
trabalho nas empresas diante da multiplicidade de demandas que se apresentam nos espaços ocupacionais.

É fundamental ter clareza dos nossos objetivos profissionais nas instituições para desempenhar bem as funções que nos cabem e desenvolver argumentos consistentes para a sua manutenção, bem como para recusar o que não nos cabe realizar. Sendo assim, é importante compreender como as empresas organizam as suas demandas, as quais dependem do tamanho, importância, ramo de atividade da instituição, dentre outros aspectos. Apesar dessas possíveis variações do modo de exercer a profissão, os nossos compromissos ético-políticos e atribuições privativas permanecem e devem ser nossa precípua direção.

Esperamos que essa sistematização possa contribuir para novas trocas e para novos aprendizados, e que coletivamente possamos fortalecer a nossa profissão.

\section{REFERÊNCIAS}

ANTUNES, R. O privilégio da Servidão: O novo proletariado de serviços na era digital. São Paulo: Boitempo, 2018.

BOTÃO GOMES, M. R. As condições de trabalho, propostas e desafios para o serviço social nas empresas de consultoria. 2010. Dissertação (Mestrado em Serviço Social). Escola de Serviço Social, Universidade Federal do Rio de Janeiro, Rio de Janeiro, 2010.

BOTÃO GOMES, M. R. Consultoria Social nas empresas: entre a inovação e a precarização silenciosa do Serviço Social. Serviço Social \& Sociedade, São Paulo, n. 122, p.357-380, 2015b.

BOTÃO GOMES, M. R. Serviço Social e "consultoria” de programas de assistência ao empregado. O Social em Questão, Rio de Janeiro, ano 21, n. 42, p. 337-356, set./dez. 2018.

BOTÃO GOMES, M. R. Serviço social e consultoria empresarial: uma possibilidade de intervenção crítica? 2015. Tese (Doutorado em Serviço Social). Escola de Serviço Social, Universidade do Estado do Rio de Janeiro, Rio de Janeiro, 2015a.

BRASIL. Lei n 13.429, de 31 de março de 2017. Altera dispositivos da Lei n-6.019, de 3 de janeiro de 1974, que dispõe sobre o trabalho temporário nas empresas urbanas e dá outras providências; e dispõe sobre as relações de trabalho na empresa de prestação de serviços a terceiros. Brasília (DF), 2017.

CARDOSO, I. C.; FRANCISCO, V. M. E. Velhas moedas com novo valor: remuneração e benefícios na moderna empresa capitalista. In: MOTA. A. E. A nova fábrica de consensos: ensaios sobre a reestruturação empresarial, o trabalho e as demandas ao Serviço Social. São Paulo: Cortez, 1998.

CESAR, M. J. Empresa cidadã: uma estratégia de hegemonia. São Paulo: Cortez, 2008. 
CESAR, M. J. Serviço Social e reestruturação industrial: requisições, competências e condições de trabalho profissional. In: MOTA, A. E. (Org.). A nova fábrica de consensos: ensaios sobre a reestruturação empresarial, o trabalho e as demandas ao Serviço Social. São Paulo: Cortez, 1998.

DOHER, Ilma. O Serviço Social em empresas para além da crítica: espaços de enfrentamento e atuação profissional. E-papers, 2015.

FONTES, V. O Brasil e o capital imperialismo. Rio de Janeiro: Fundação Oswaldo Cruz, 2012.

FREIRE, L. M. B. O Serviço Social na reestruturação produtiva: espaços, programas, direções e processos do trabalho profissional. São Paulo: Cortez, 2010.

GIAMPAOLI, M. C. Contingências no trabalho do assistente social em empresas: o caso das consultorias empresariais. 2012. Dissertação (Mestrado em Serviço Social). Departamento de Serviço Social, Pontifícia Universidade Católica de São Paulo, São Paulo, 2012.

IAMAMOTO, M. V. Serviço Social em tempo de capital fetiche: capital financeiro, trabalho e questão social. Cortez, 2010.

IAMAMOTO, M. V.; CARVALHO, R. Relações Sociais e Serviço Social no Brasil: esboço de uma interpretação histórico-metodológica. São Paulo: Cortez, 2013.

LINHART, D. A desmedida do capital. São Paulo: Boitempo, 2007.

LINHART, D. Modernização e precarização da vida no trabalho. In: ANTUNES, R. (Org.).

Riqueza e miséria do trabalho no Brasil. Vol. III. São Paulo: Boitempo, 2014.

MARX, Karl; ENGELS, Friderich. Textos. São Paulo: Edições sociais 1977.

MONTÃNO, C.; DURIGUETO, M. L. Estado, classe e movimento social. São Paulo: Cortez, 2010.

MOTA, A. E. O feitiço da ajuda: as determinações do Serviço Social na empresa. São Paulo: Cortez, 1991.

MOTA, A. E.; AMARAL A. S. Reestruturação do capital, fragmentação do trabalho e Serviço Social. In: MOTA, A. E. (Org.). A nova fábrica de consensos: ensaios sobre a reestruturação empresarial, o trabalho e as demandas ao Serviço Social. São Paulo: Cortez, 1998.

NETTO, J. P. Crise do capital e consequências societárias. Serviço Social e Sociedade, São Paulo: Cortez, v. 111, p. 413-429, jul./set. 2012. 
Márcia Regina Botão Gomes Coordenadora do projeto de pesquisa As novas faces do Serviço Social nas empresas do século XXI: mudanças nas formas de contratação, organização do trabalho e requisições profissionais.

Doutora em Serviço Social (UERJ- 2015), Mestre e Serviço Social (UFRJ-2010), Graduada em Serviço Social (UFRJ -1999). Professora do curso de Serviço Social da PUC-Rio, Pós-graduação e graduação.

Pesquisadora do trabalho profissional do Serviço Social em empresa.

Maria Elizabeth Freire Salvador coautora do artigo e integrante da comissão de empresa do CRESS-RJ.

Assistente Social, Mestre em Serviço Social pela Pontifícia Universidade Católica do Rio de Janeiro (PUC-Rio). Docente do curso de Serviço Social da Pontifícia Universidade Católica do Rio de Janeiro (PUC-Rio).

Dácia Cristina Teles Costa coautora do artigo - presidenta do CRESS-RJ.

Mestre em Serviço Social (UFRJ), Assistente Social da empresa Petrobras (Petróleo Brasileiro S/A) e Presidenta do Conselho Regional de Serviço Social do Rio de Janeiro (CRESS-RJ). 